\title{
Biocapital, biopolítica e biossocialidades no contexto global de gênero: revisão teórica e evidências*
}

Liliana Acero**

\begin{abstract}
Resumo
$\mathrm{O}$ artigo discute tendências dominantes e contra tendências em genética e biotecnologia da saúde, seguindo principalmente as perspectivas teóricas de Rose. Haraway e Braidotti e seus seguidores, reformuladas para o contexto do desenvolvimento, $e$ em direção a uma recriação positiva das relações de gênero $e$ do desenvolvimento sustentável. Os elementos conceituais dessas teorias incluem: a ascensão do cidadão biopolítico, o desenvolvimento de biossocialidades e a construção da biopolítica focada na responsabilidade genética e na ética do corpo.
\end{abstract}

Palavras-chave: Relações de Gênero, Desenvolvimento Sustentável, Biotecnologia da Saúde, Genética, Corpo.

\footnotetext{
* Recebido em 26 de setembro de 2019, aceito em 09 de outubro de 2020.

** Professora Visitante Estrangeira Senior Programa de Pós-graduação em Políticas Públicas, Estratégias e Desenvolvimento (PPED), Instituto de Economia (IE), Universidade Federal do Rio de Janeiro (UFRJ), Rio de Janeiro, RJ, Brasil. lilianaacero2009@gmail.com / http://orcid.org/0000=0002-5460-3363
} 
Biocapital, Biopolitics, and Biosocialities in a Global Gender Context: Theory and Evidence

\begin{abstract}
This article discusses dominant trends and countertrends in genetics and biotechnology for healthcare, based mainly on the theoretical approaches of Rose, Haraway, and Braidotti and their followers, which are reformulated for the context of development and directed towards a positive recreation of gender relations and sustainable development. The principal conceptual elements of these theories include: the rise of the biopolitical citizen, the development of biosocialities, and the construction of biopolitics focused on genetic responsibility and body ethics.
\end{abstract}

Keywords: Gender Relations, Sustainable Development, Biotechnology for Healthcare, Genetics, Body. 


\section{Introdução}

Biotecnologias vermelhas animais e humanas ${ }^{1}$,suas contrapartes institucionais e cenários políticos afetam a vida das pessoas, impactam seus meio-ambientes e, mais imediatamente, seus corpos, e por sua vez, são impactados por elas. Pesquisar seus efeitos sociais de gênero é uma maneira de contribuir para preencher um vácuo relativo dentro das teorias críticas de desenvolvimento e gênero, para que os sujeitos sociais ganhem maior visibilidade na defesa da equidade de gênero no desenvolvimento, e sejam incluídos, em especial as mulheres, de forma mais sistemática na participação pública e no engajamento inclusivo em relação a essas tecnologias.

A nova genética e a biotecnologia mediam substantivamente as relações de gênero $e$ o meio ambiente nas formas de vida contemporâneas; elas reformulam corpos e redefinem direitos (ex. Lock, 2015; Dickenson, 2016). Além disso, contribuem para a criação de novos arranjos institucionais e a formulação de políticas e regulamentação em nível comunitário, nacional e global, e levantam inúmeras questões culturais e eticamente controversas baseadas em gênero, classe, idade, raça, etnia e orientação sexual (ex. Roseman et al., 2018). As narrativas críticas, tanto acadêmicas como de advocacia, devem ser consistentemente focadas para enfrentá-las, e os esquemas regulatórios para a genética $e$ a biotecnologia da saúde em países emergentes requerem um redesenho adequado - do ponto de vista do gênero e dos direitos - para dar conta dessas mudanças.

A participação do público, e em especial das mulheres, na democratização da ciência $e$ da medicina nas áreas em estudo, dentro das economias emergentes, têm uma escassez de espaços adequados de engajamento e expressão, com algumas exceções (ex. Nunes Batista et.al., 2019; Hwang; Sleeboom-Faulkner, 2014). Mas, para colher os benefícios e minimizar os riscos e incertezas dessas tecnologias, é necessário maior monitoramento estatal e controle social.

No presente artigo, primeiro, se desenvolve uma breve reflexão das bases conceituais $e$ metodológicas do estudo e se delineiam as principais tendências na relação entre as mudanças econômicas e o biocapital nas economias avançadas e emergentes. Apresentam-se, na sequência, as articulações entre a teoria $e$ as evidências e uma discussão sobre as reformulações do corpo humano e das mulheres. Ilustram-se, a seguir, experiências com novos estilos de governança e de vida biossociáveis, especialmente aqueles iniciados informalmente por mulheres e por grupos de pacientes. Conclui-se com uma reflexão proativa em relação à recriação desse novo paradigma da genética e da biotecnologia da saúde pelas mulheres em nível global.

\section{Abordagem conceitual}

Alguns cientistas sociais relevantes e os formuladores de políticas de desenvolvimento convencionais, muitas vezes, mantêm visões estreitas sobre o novo paradigma das biotecnologias da saúde baseadas na genética e nas células tronco. As biotecnologias são consideradas como uma solução única ou preferida para as atuais intervenções nas crises capitalistas e do desenvolvimento (Niosi et.al., 2013), ou então, subestimam-se severamente seus riscos e incertezas para o redesenho de futuros modos de vida sustentáveis (Thorsteinsdóttir et al., 2004).

$\mathrm{Na}$ corrente convencional (ou "extrópica") dos pós-humanistas, considera-se que essas tecnologias oferecem uma contribuição "tecnofílica" para aprimorar e fazer evoluir a espécie humana, até a sua eventual extinção ou obsolescência, devido à sua futura expansão e replicação (ex. More, 1999); ou seja, essas tecnologias formariam parte central da evolução necessária para a perfeição gradual do ser humano ${ }^{2}$. Por sua vez, há também autores radicalmente críticos dessas biotecnologias, que descrevem a humanidade como condenada por seu envolvimento em "formas divinas de interferir na natureza", e descartam de modo quase integral o novo paradigma, ou bem, adotam uma posição tecno fóbica e consideram essas tecnologias como responsáveis, no futuro, de uma total falta de humanidade (Kass, 2007). Ambos os caminhos se caracterizam por um

\footnotetext{
1 A cor vermelha refere-se ao sangue humano e animal.

2 Essa abordagem é representada, por exemplo, pelo Extropy Institute [http://www.extropy.org - acesso em $10 \mathrm{de}$ abril de 2019]. Para uma crítica a essa aproximação, consultar, por exemplo, Thacker (2003).
} 
determinismo tecnológico que atribui à tecnologia a solução de todos os problemas ou todos os males, a última, uma posição frequente entre as soluções tecnológicas propostas por algumas feministas norte-americanas (Darling, 2006; Darnovsky, 2014).

Informa a análise teórico-documental e ilustrativa a seguir, um caminho do meio ou da moldagem social da tecnologia, no qual se reconhecem os elementos históricos e sociais envolvidos na criação, melhora e regulação do uso das tecnologias. O caminho escolhido é mais afinado com as posições das feministas europeias (Dickenson, 2008; 2016), e pode oferecer elementos relevantes para aprofundar a discussão no Brasil nessa área. A aproximação a ser formulada foi pensada em vistas a uma recriação positiva do novo paradigma para contribuir à equidade de gênero no desenvolvimento sustentável.

O objetivo deste artigo é discutir as tendências e experiências contemporâneas dominantes e contra tendências em genética e biotecnologia da saúde, seguindo principalmente as perspectivas teóricas de Rose (2001; 2007; 2013), Haraway (1991a; 1991b; 1997), Braidotti (2013; 2015) e alguns de seus seguidores chave, reformuladas para o contexto de desenvolvimento. Essas teorias, na minha opinião, podem vir a contribuir na avaliação equânime e esperançosa da atual fase da inovação na área, das suas implicações para a mudança socioeconômica e para as vidas das pessoas, em especial das mulheres - muitas das quais, se debatem atualmente entre a utilização acrítica e a transformação criativa dessas tecnologias.

Os elementos conceituais centrais das principais teorias revisadas incluem: a ascensão do cidadão biopolítico, o desenvolvimento de biossocialidades e a construção de novas formas de política - como na biopolítica - focadas na responsabilidade genética e ambiental e na ética do corpo. O artigo explora elementos teóricos para uma discussão sobre esses assuntos - referenciados através de evidências e exemplos - do ponto de vista das relações de gênero e à luz de algumas práticas sociais em países centrais e emergentes. Também pretende ilustrar as carências de informação em países emergentes, em temas associados à reformulação teórica das relações de gênero e ao desenvolvimento de ações pertinentes à equidade de gênero na frente da "revolução" genética e da biotecnologia da saúde.

Apesar de algumas diferenças conceituais, os autores revisados como um todo refletem sobre a nova genética e a biotecnologia da saúde de maneira flexível e criativa, além das teorias e ideologias convencionais, e contextualizam as múltiplas maneiras pelas quais a "vida em si" está sendo transformada diariamente pelas tecnociências. Donna Haraway (1991a), em especial no Manifesto Ciborgue do ano de 1985, se apropriou da terminologia ciborgue - desenvolvida nas pesquisas da NASA na era da corrida espacial, para definir os organismos cibernéticos que auxiliaram os astronautas na sobrevivência no meio ambiente extraterrestre - e formulou-a "como um gesto performativo em oposição à necessidade [de recorrer as] das histórias das origens" (Haraway,1991a:80-81). Os ciborgues seriam organismos de sínteses orgânica e cibernética com capacidades aprimoradas pela tecnologia artificial.

O foco da aproximação teórica e das pesquisas de Haraway, após esse Manifesto, se centrou no estudo das formas pelas quais, em especial as biociências como a imunologia, a genética molecular $e$ as ciências ecológicas, na interface entre humanos, máquinas e Natureza, constantemente produzem novos "nós materiais-semióticos" no debate do que importa como humanos. Objetos híbridos únicos, como o camundongo transgênico, o mapa genômico e o vírus HIV/AIDS, segundo ela, reformulam o conceito da divisão estrita entre sujeitos ativos e objetos passivos, e os desenvolvimentos na genética nos desafiam a encontrar um suposto limite ou território bem definido da espécie humana.

Haraway reformulou o discurso do pós-humanismo convencional de um modo crítico, em nível cultural, político e de gênero, mas sem abandoná-lo totalmente. Utilizou um discurso híbrido, irônico e lúdico para mostrar as tensões produtivas entre a contingência e a emergência de novas formas de vida e sua interrelação com os humanos, de um modo que desafia as formas históricas de regular a relação entre humanos e não humanos, biologia e tecnologia.

Ademais, em suas abrangentes pesquisas, Haraway discutiu a "objetividade" do conhecimento científico, introduzindo a ideia da localidade dos conhecimentos ou os conhecimentos situados por gênero, raça, idade, orientação sexual e outros: “(...) conhecimentos 
críticos, parciais, localizáveis, sustentando a possibilidade de redes de conexões denominadas "solidariedade na política e conversas compartilhadas na epistemologia'", e propôs uma perspectiva "não inocente", ou seja, sensível às relações de poder que toda conversa abrange (Haraway, 1991b:191). A autora considera que, para participarmos de conversas responsáveis e objetivas, precisamos nos situar e fazer uma tradução sensível ao poder, que requer, entre outras coisas, um "distanciamento apaixonado" (MacDowel dos Santos, 1995:67).

Politicamente, os/as autores/as revisados/as em geral, direta ou indiretamente, defendem uma política afirmativa baseada em uma ética que pode promover a coesão social e o respeito pela diversidade e as vulnerabilidades no crescimento sustentável. Por exemplo, Braidotti (2015) enfatiza a importância de construir uma subsistência desejável no futuro por meio da recriação da genética e das biotecnologias reguladas e socialmente controladas; e encoraja as mulheres a adotarem uma perspectiva "materialista vital" dentro da política afirmativa global.

A acadêmica fundamenta sua posição em uma perspectiva pós-humanista crítica, que inclui uma posição pós-estruturalista e se opõe ao antropocentrismo europeu, masculino, branco, expansionista e colonizador. Ela considera que esse tipo de abordagem nega espaço e equidade às diversidades, às multiculturalidades e às regiões geográficas, como também prejudica o meio ambiente. Em contraste, ela se posiciona desde uma ontologia que desafia a supremacia do humano, do ato de equacionar subjetividade com consciência racional universal e de afirmar a existência de uma "binaridade assimétrica" entre as espécies humana e animal. Discutindo as biociências, Braidotti (2013:16) afirma que:

Nós necessitamos abraçar o não lucro como um valor chave na produção contemporânea de conhecimentos, mas essa gratuidade se inter-relaciona com a construção de horizontes sociais de esperança e, portanto, constitui um voto de confiança na mera sustentabilidade do futuro [...]. O futuro não é, nem mais nem menos, que a solidariedade intergeracional, a responsabilidade com a posteridade, e é também, um sonho compartilhado ou uma alucinação consensuada.

\section{Construção metodológica}

O artigo foi construído com base numa pesquisa bibliográfica e documental, primeiro, através de uma revisão da literatura mais influente dos autores mencionados e de seus seguidores, procurando detectar semelhanças na sua aproximação aos conceitos do biocapital, da cidadania biopolítica e das biossociabilidades. Segundo, foram revisados textos de autoras feministas ${ }^{3}$, e outros, nas áreas de Ciência, Tecnologia e Sociedade (CTS) e dos Estudos de Gênero em Ciência e Tecnologia (EGCT), e que utilizam os conceitos selecionados na análise socioeconômica da genética, a fertilização assistida, a medicina regenerativa $e$ a biotecnologia da saúde em geral. Finalmente, procuraram-se evidências ilustrativas em relação: à reformulação do corpo feminino decorrente da nova genética e das pesquisas com células tronco e aos grupos da sociedade civil, liderados por mulheres ou pacientes, na evolução e/ou a resistência a essas práticas.

Priorizaram-se as informações geradas em países emergentes, em especial na América Latina, mas a escassez de pesquisa em nossos países nessa área é grande - constituem exceções algumas análises sociais de diagnósticos genéticos e principalmente, da fertilização assistida. Assim, incluíram-se referências a estudos nos países avançados, que mostram as principais lacunas na literatura brasileira e latino-americana, assim como, contribuem para a definição de possíveis novas linhas de pesquisa e advocacia.

\footnotetext{
3 Principalmente, encontrados em algumas revistas acadêmicas indexadas no sistema Qualys da Capes, como são, para o Brasil: Tecnologia e Sociedade, Ciência e Saúde Coletiva, cadernos pagu, Revista de Estudos Feministas e Physis, Revista de Saúde Coletiva; para América Latina, em especial, Revista Iberoamaericana de Ciência, Tecnologia e Sociedade, Interciência e Revista Tapuya; assim como, de revistas internacionais relevantes: Biosocieties, Science as Culture, New Genetics_and Society, Social Studies_of Science e Public_Understanding_of Science.
} 


\section{Biocapital e desenvolvimento}

A última década testemunhou um aumento dramático nos recursos econômicos acumulados e nos bens e serviços desenvolvidos através da transformação de materiais biológicos em nível molecular, isto é, de plantas, animais e células humanas, pela expansão das biociências e das biotecnologias associadas. Essas inovações floresceram dentro de um conjunto hegemônico de relações sociais no mercado que impulsionam, de novas maneiras, a acumulação global de capital.

As biociências, desde o final do século passado, se organizaram cada vez mais em torno de novas técnicas genéticas e celulares para manipular a vida, que está sendo transformada em "biovalor":

Biovalor refere-se ao rendimento da vitalidade produzido pela reformulação biotecnológica dos processos vivos. A biotecnologia ganha importância nos processos vivos, induzindo-os a aumentar ou mudar sua produtividade segundo linhas especificadas, intensificando suas capacidades de autorreprodução e automanutenção [...] Além disso, ocorre em gral não in vivo, mas in vitro, uma vitalidade desenvolvida no laboratório. [...] Em suma, a biotecnologia encontra pontos de inserção entre sistemas vivos e não vivos, onde formas novas e contingentes de vitalidade podem ser criadas, capitalizando a vida (Waldby, 2002:310).

As formas de vida tornam-se objetos de troca no mercado, inaugurando a "era do biocapital" (Sunder Rajan, 2008a; Birch; Tyfield, 2012), ou seja, uma etapa caracterizada pelas muitas formas em que o capital se inter-relaciona com a biotecnologia para extrair o biovalor, regulamentar as trocas econômicas e gerar novas formas de ganhos econômicos, como é definido, por exemplo, por Yoxen (1981:112):

[...] Não apenas uma maneira de usar seres vivos que podem ser rastreados até as origens neolíticas da fermentação e da agricultura, [mas como] uma tecnologia controlada pelo capital, [...] um modo específico de apropriação da natureza viva, literalmente capitalizando a vida.

O conceito de biocapital evolui da definição inicial de biopoder de Foucault (Rabinow; Rose, 2003). Os estados nacionais e coloniais colocam a vida e seus mecanismos na ordem dos cálculos explícitos; eles lhes conferem o biopoder. Os corpos de indivíduos e populações são transformados, regulados e gerenciados através do poder disciplinar.

Em contraste, durante o século XXI, o biopoder contemporâneo atua através e não no corpo - ou na disciplina do corpo como estudado por Foucault - o que reflete uma relação mais estreita e intrínseca entre bioeconomia e biopolítica (Rabinow; Rose, 2006). Essas mudanças, segundo Rose (2007), consolidam-se através de cinco processos científicos e socioeconômicos diferentes: a molecularização, a otimização, a subjetivação, o conhecimento somático dos especialistas e as economias da vitalidade.

Alguns autores, em contraponto, sustentam que o biocapital e a biopolítica, em especial nos países periféricos e com passado colonial, desenvolvem nas crises sistêmicas e com um Estado de exceção como a regra, uma passagem para a necropolítica: uma política centrada na violência, na militarização e na produção da morte em larga escala (Membe, 2016). O sujeito supérfluo, cuja força de trabalho já não é mais necessária ao modo de reprodução do capital em sua fase atual converte-se em portador de uma "vida sem valor" (Agambem, 2010:134), uma vida indigna de ser vivida. Nesse estágio, as formas de sociabilidade próprias do capitalismo entram em estágio de decomposição. Na bionecropolítica isso poderia vir a se refletir eventualmente, por exemplo, na coerção para a apropriação forçada ou compra de materiais biológicos em grande escala de sujeitos vulneráveis e "descartáveis".

Os cálculos biopolíticos têm organizado cada vez mais um grande número de iniciativas econômicas que visam a criação de valor, mercados, riqueza, ganhos materiais e informações biológicas. As entidades biológicas que habitam esse cenário corresponderiam, segundo Rose, não apenas aos indivíduos e populações já analisados por Foucault, mas também às células, moléculas, genomas e genes. 
[...] A vitalidade foi decomposta em uma série de objetos distintos e discretos, que podem ser estabilizados, congelados, armazenados, acumulados, trocados, comercializados ao longo do tempo, através do espaço, através de órgãos e espécies, em diversos contextos e atividades ao serviço de objetivos bioeconômicos (Rose, 2007:67).

A extração do biovalor do cidadão biopolítico através das novas técnicas genéticas $e$ genômicas é consumada por três diferentes processos Primeiro, a própria vida produz valor econômico. Em segundo lugar, a manipulação da vida gera valor, por exemplo, para a melhoria da saúde. Terceiro, a produção de riqueza e de saúde está intimamente relacionada com valores éticos (Rose; Novas, 2005). Atualmente, o biopoder une práticas biopolíticas ${ }^{4}$ que, por sua vez, articulam mudanças econômicas e biomédicas e levam a comportamentos sociais, tais como: a cidadania biopolítica, a responsabilidade genética, a ética corporal e a biosociabilidade (Rabinow, 1996; Rabinow; Rose, 2006) $)^{5}$.

Especialistas feministas propuseram que o biocapital também faz parte dos processos de reprodução biológica contemporâneos. Essa nova riqueza depende de:

[...] Uma forma de extração [de biovalor], que consiste no isolamento e mobilização da agência reprodutora primária de partes específicas do corpo, especialmente das células, de uma forma não tão diferente daquela descrita por Marx [...] que analisou o papel central que a terra ocupa na agricultura (Franklin; Lock, 2003:8).

Quando os modos fordistas de acumulação de capital (pela manufatura em massa) em nível nacional declinaram em lucratividade após o boom econômico do pós-guerra, o capitalismo recorreu a outras formas de acumulação flexível ou pós-fordista, usando novos conhecimentos científicos como fonte de valor. Esse processo foi apoiado pela disseminação das teorias sobre a economia do conhecimento, historicamente baseadas em tecnologias de informação e comunicação (TICs) e, posteriormente, pela expansão dos conhecimentos aplicados das biociências. As novas tecnologias emergentes tornam-se cada vez mais uma plataforma necessária para que uma ampla gama de setores industriais e de serviços permaneçam globalmente competitivos.

As economias emergentes também forneceram apoio financeiro público substancial para a pesquisa científica $e$ a inovação nos setores biotecnológicos verde (agrícola) e vermelho (animal/humano). No Brasil, a inovação local em saúde, por exemplo, cresceu nos anos 2000, com a engenharia genética de vírus e bactérias de diversas culturas e a fundação do Instituto do Genoma Humano em São Paulo (Harvey; Mc Meekin, 2007).

A economia global de mercado é questionada em momentos diversos pela volatilidade das instituições financeiras e pela falibilidade de mercados e governos (Harcourt, 2010). As empresas de biotecnologia start-up e spin-off de centros de pesquisa universitários foram, antes da última década, fortemente dependentes do capital de risco dos mercados financeiros internacionais no desenvolvimento e comércio de produtos futuros, ou seja, para os processos em fase de pesquisa, mas ainda não em fase de comercialização ${ }^{6}$. A crise econômica de meados da década passada das economias avançadas questionou a base deste modelo de acumulação de biocapital, bem como a sustentabilidade dos enquadramentos. E assim, abriu espaço, até hoje, para repensar sua evolução no Sul e seus impactos ambientais e comunitários.

\section{Articulações entre a teoria $e$ as evidências}

Nas seções a seguir, se coloca um leque amplo de exemplos, em relação aos corpos humanos $e$ as relações sociais, em vários assuntos centrais que são atingidos pelo desenvolvimento do

\footnotetext{
4 Ou seja, exercidas através da cidadania biopolítica, na qual os cidadãos e as instituições deparam-se com que as suas ações políticas são mediatizadas pela biologia e pelas novas construções emergentes e contingentes entre as espécies e as tecnologias inovadoras.

5 O novo conceito de biossocialidade ou biossociabilidade representa o processo pelo qual a genética, a imunologia e os estudos ambientais tornam-se veículos principais para a infiltração das tecnociências, do capitalismo e da cultura; processo geralmente chamado Natureza por representantes da modernidade.

6 Dados da pesquisa em andamento sob a minha coordenação.
} 
biovalor, da biopolítica e das biossociabilidades. A opção por uma análise de vários exemplos ${ }^{7}$ parece ser mais adequada aos objetivos do artigo - de mostrar a variedade de situações em que essas formas específicas no capitalismo contemporâneo aparecem e impactam diferentes aspectos do cotidiano, da saúde e da qualidade de vida, em especial, das mulheres.

Pretende-se fundamentar o argumento central do artigo de que as novas tendências em biociências e biotecnologia precisam ser conscientizadas, regulamentadas e socialmente controladas pelo público amplo e os grupos de mulheres, $e$ incluídas de forma teórica nas abordagens feministas e na advocacia para aumentar a consciência cidadã, usufruir de seus benefícios e diminuir ou afastar suas piores consequências - aquelas de cunho bionecropolítico. Ilustram-se formas existentes de democratizar o conhecimento e as práticas nessa área. Os conhecimentos "situados", se incluídos nas pesquisas e terapias da saúde de base genético-molecular, propenderão a satisfazer necessidades de grupos sociais longamente excluídos ou subordinados.

As mulheres não permanecemos como inertes espectadoras dessas transformações, $e$ as oposições e recriações existentes apontam na direção de mudanças. Ainda que elas sejam apenas sementes de transformação, merecem ser resgatadas, salientadas e aprofundadas de modo teórico e empírico.

\section{O corpo humano}

Os corpos humanos e partes do corpo também são parcialmente propensos à "tecnociência personalizada" contemporânea. O corpo humano é socialmente redefinido e concebido como um grupo de partes, órgãos, células e tecidos que podem ser reparados, substituídos e regenerados. Por um lado, o corpo torna-se mais clinicamente controlável, por exemplo, pode ser visível internamente e publicamente através do uso de técnicas de ultrassom e scanners. Por outro lado, o conhecimento sobre o corpo humano aumenta e é extensivo a uma ampla variedade de pessoas que podem usá-lo em seu benefício, como é proposto por algumas das teóricas revisitadas (ex. Dickenson, 2016).

Presenciamos uma reformulação científica recente do determinismo genético que caracterizou os anos iniciais do sequenciamento do genoma humano. Há, na atualidade, uma relativa virada nas ciências genéticas no sentido de colocar maior ênfase nos fatores epigenéticos dos processos de transformação biológica - ou seja, aqueles que se relacionam ao meio ambiente interno em que funcionam os genes. Desse modo, o estudo dos aspectos sociais, de gênero e do meio ambiente externo em que os corpos humanos (e animais) evoluem, também gradualmente cobra maior relevância em nível da pesquisa genética (Lock, 2015; Rose, 2013). Nesse sentido, é mais bem aceito nos campos científicos associados que os genes se expressam segundo as circunstâncias das pessoas, ex. idade, sexo, situação socioeconômica, qualidade de vida e do ar, água e outros, $e$ segundo os níveis de estresse experimentados pelos indivíduos e associados, de modo complexo, a múltiplas variáveis (Kenny; Müller, 2017).

Esse novo foco nas pesquisas oferece a possibilidade de incluir determinantes sociais e de gênero no estudo genético e molecular da saúde humana e feminina - diferenciados por etnia, situação socioeconômica, orientação sexual e raça. A localidade dos conhecimentos "situados" e os "nós materiais-semióticos" no debate do que importa como humanos - segundo a perspectiva já discutida de Haraway (1991a, b) - podem vir a se transformar em resultados e potenciais aplicações em terapias que respondam de forma mais eficiente e adequada a uma variedade diferenciada de sujeitos sociais.

Os corpos femininos são moldados dentro de experiências sociais $e$ individuais na permanente reconstrução de identidades e subjetividades de gênero. $O$ senso de posse $e$ autocontrole das mulheres teve que ser historicamente recuperado. Dickenson (2008) analisa as formas específicas em que, com a genética molecular, todos os corpos começam a ser tratados como antigamente eram apenas os corpos femininos: "a feminização dos corpos". Todos os corpos humanos tendem a perder de forma transversal a liberdade, quando padrões de controle baseados nas biotecnologias da saúde se generalizam dentro da sociedade.

\footnotetext{
7 Em vez de se apresentarem resultados específicos de um estudo de caso.
} 
Esta última situação é consequência de três processos principais: a genetização da saúde, a universalização e a normalização da reengenharia gradual do corpo humano ${ }^{8}$. Indivíduos que discordam ou transgridem práticas médicas socialmente legitimadas podem ser suscetíveis à marginalização, à exclusão do sistema público de saúde, ou então suas demandas podem ser simplesmente silenciadas, como por exemplo, ainda são algumas das expressões de orientação sexual LGBTQI+, ou no caso de muitas pessoas com capacidades diferenciais (Preciado, 2006; Luciano; Chen, 2015). Nesse sentido, a bionecropolítica atua de forma negativa sobre os direitos das diversidades discriminadas ou daquelas populações menos privilegiadas ao se "normalizarem" dinâmicas da reengenharia do corpo.

Uma técnica recém-normatizada, por exemplo, é geralmente tratada como: "a única ou melhor maneira de fazer as coisas". Os exemplos abrangem: a ampla expansão do diagnóstico genético pré-natal e neonatal, relatado de forma brilhante na obra pioneira de Rayna Rapp (2000); o uso generalizado do diagnóstico genético de pré-implantação para a seleção de embriões viáveis ou por sexo para a fertilização assistida (Risoy; Simes, 2015); os kits de diagnóstico genético personalizado e acessíveis via internet (Darnovsky, 2014), assim como, a expansão de terapias e medicamentos de base celular para a regeneração de partes do corpo. Mais recentemente, se inclui também a edição de genes para eliminar doenças potenciais em adultos e, por vezes, realizado nas células germinais - ou seja, uma via de transmissão das mudanças de forma intergeracional, um aspecto de características tanato-políticas. Ademais, essas práticas não se impõem de modo automático e geram reações sociais alternativas e contundentes, com foco em o que Braidotti (2015) definiu como "solidariedade intergeracional" ou "a responsabilidade com a posteridade". Há de se recordar a relevância da denúncia dos sucessivos escândalos recentes associados a algumas dessas práticas, por exemplo, na China, com o nascimento de gêmeas com a edição de genes de suscetibilidade ao HIV/AIDS, que termina com a prisão do cientista responsável (Dickenson; Darnovsky, 2019).

Entretanto, a assimilação de diferentes tipos de pessoas e gêneros em uma categoria mais uniforme de práticas corporais, oferece também espaço para aumentar a ressonância, a comunalidade, a cooperação e a solidariedade entre gêneros, diversidades, raças e orientações sexuais. As próprias tecnologias têm o potencial de aumentar ou reduzir as escolhas individuais $e$ coletivas, mas muitas vezes, fazem parte de um regime sociotécnico que se concentra no último aspecto: o biopoder atuando através do corpo. As mulheres são pressionadas ou induzidas socialmente a optar por não dar à luz uma criança com síndrome de Down, escolher selecionar um embrião saudável ou mais apto durante a reprodução assistida, armazenar sangue do cordão umbilical e da placenta durante o parto, e ainda, no futuro próximo possivelmente, a aceitar editar genes na reprodução e diminuir algumas suscetibilidades genéticas. Mas as mulheres também têm novos direitos quando se tornam portadoras e guardiãs de uma maior responsabilidade genética $e$ genômica; uma oportunidade de desenvolver uma participação ativa e informada como cidadãs biopolíticas.

As tendências globais na extração, colheita e tráfico de óvulos humanos para fertilização assistida e pesquisa com células-tronco foram estudadas, no decorrer de décadas, por mulheres acadêmicas e ativistas feministas que produziram evidências substanciais sobre essas práticas ilegais (Waldby, 2008; Eisendel; Adamson, 2012). Autoras feministas documentaram o desconforto e os altos riscos -frequentemente fatais —associados à doação e à partilha de óvulos (Beeson; Lippman, 2007; Petropanagos et al., 2015), assim como, analisaram as práticas economicamente motivadas ou abertamente coercivas de extração de óvulos, exercidas sobre mulheres vulneráveis de setores pobres ou minorias étnicas em diferentes contextos, algumas ligadas à prostituição ou ao tráfico de mulheres. Mulheres fornecedoras de materiais genéticos formam parte da criação de uma

\footnotetext{
8 Ainda, e apesar da relevância recente dos estudos em epigenética já mencionados, um maior destaque é atribuído aos determinantes genéticos da saúde e do bem-estar, do que aos determinantes sociais: uma genetização da saúde. Uma vez comprovada a eficácia de uma nova técnica genética, originalmente desenvolvida para um número reduzido de casos clínicos críticos, seu uso se estende ao sistema de saúde como um todo. Como resultado, há um código único de prática: o processo de universalização de uma técnica. Os principais protocolos terapêuticos e normas sociais são então transformados, resultando em um processo de normalização das técnicas originalmente consideradas como inovadoras.
} 
dinâmica de tendência bionecropolítica, em que as vidas de umas servem às das outras, em especial, às mais privilegiadas. Mas as vulnerabilidades subjacentes podem ser ativamente denunciadas e controladas, afincando-se em "um território bem definido da espécie humana" como colocado por Haraway (1997:10).

Uma serie documental da $\mathrm{BBC}$ também denunciou o tráfico de fetos humanos com fins de pesquisa que, procedentes da Ucrânia, se vendiam a uma clínica de Barbados ${ }^{9}$. Esse tipo de pesquisa gera evidências úteis não apenas para estabelecer limites normativos para essas práticas, mas também para contestar e democratizar o conhecimento científico e médico convencional, assim como para seu enquadramento em uma ética alternativa do corpo feminino.

Estima-se que, desde o ano 2000, centenas de milhares de pacientes têm recebido tratamentos experimentais não comprovados com terapias e medicamentos celulares, oferecidos a preços que variam, em geral, entre 5.000 e 50.000 dólares dos EUA, mas que também chegam a custar até 100.000 dólares cada um (McMahon, 2014). Os estudos a acadêmicos do turismo médico europeu e norte-americano aos países emergentes, concentraram-se principalmente na China e na Índia (Sleeboom-Faulkner, 2016; Monsores et al., 2016).Se esse tipo de análise for replicado em contextos de outras economias emergentes, é possível que se constatem práticas semelhantes. Há necessidade urgente de desenvolver mais pesquisas nessa área, em especial na América Latina.

Existem informações sobre esse tipo de práticas acontecendo no Equador e em Barbados, segundo o Centro Americano de Células Madre y Anti-Envejecimiento (Pérez Requejo; Aznar Lucea, 2012). Na Argentina, - segundo identificam Bortz et al. (2019) - algumas estimativas consideram que, aproximadamente dez instituições oferecem tratamentos não comprovados para aplicações estéticas, como autotransplantes e, em menor grau, para "curar" feridas do coração, da medula óssea, assim como para doenças neurodegenerativas e metabólicas. Além disso, existem nesse país, atualmente, representantes de clínicas - em especial da China, mas também dos EUA que oferecem tratamentos locais não comprovados para doenças raras ou terminais. Com a ajuda da imprensa, a opinião pública nacional tem sido influenciada a favor da utilização de tratamentos experimentais de base celular. Alguns juízes, face à legislação incompleta na área $e$ às demandas desesperadas por cura e proteção legal da parte dos pacientes, têm forçado os serviços privados de saúde a pagar os custos de tratamentos não comprovados. Alternativamente, tem se desenvolvido campanhas públicas de beneficência para contribuir com os pacientes a afrontar os altos custos desses tratamentos experimentais.

Mais recentemente, diversas dessas práticas foram denunciadas em países avançados, apesar de que esses países tendam a contar com uma regulação mais sistemática e abrangente no assunto do que na América Latina. Ilustram essa situação, por exemplo, o caso da clínica Stamina na Itália (Margottini, 2013); o da clínica alemã (X Cell-Center) de Dusseldorf - que tratava também crianças (Mendick; Palmer 2011) e o da Stem Cell Clinic da Florida. Esta foi interpelada pela Food and Drug Administration (FDA) do EUA, pelo uso de injeções oculares para a "cura" da degeneração macular de três mulheres que, como resultado do tratamento, ficaram cegas (Kuriyan, 2017). Estima-se também, que atualmente existem 570 clínicas nos EUA vendendo terapias celulares autólogas transplantes de células-tronco extraídas em $61 \%$ dos casos do tecido adiposo do mesmo paciente não autorizadas pela FDA, a um preço médio de 15.000 dólares dos EUA por aplicação, em especial, para aliviar a inflamação em danos ortopédicos (Tsuji et al., 2014).

A comunidade científica internacional, bem como instituições de ética em pesquisa, associações várias de medicina e ONGs selecionadas - como o Instituto de Harvard de Células Madre - moralmente preocupadas com essas práticas não comprovadas, vem há tempo tomando iniciativas influentes para contribuir no desenho de regulação global atualizada (ISSCR, 2008; ICMS, 2015). A situação não deixa de ser altamente problemática, em termos do que pode significar para a saúde coletiva global e os sistemas públicos de saúde. No caso das mulheres dos países emergentes, em especial das mais vulneráveis, é ainda mais preocupante, como sendo fornecedoras potenciais de materiais biológicos e/ou consumidoras dos produtos não comprovados.

9 O Institute for Regenerative Medicine denuncia que provocou seu fechamento ao público. Consultar Price S. (2012). Nations News [http://web.archive.org/web/20080128173958/ - acesso em: 29 jul. 2019]. 
Somadas às dificuldades diárias e incertezas de subsistência ou pura sobrevivência, essas mulheres agora também podem vir a enfrentar novas ameaças: o abuso, em novas formas, de um bem preciosamente recuperado, seus corpos, tecidos, genes e células. Agora, uma coleta de saliva ou sangue de rotina é suficiente para realizar um teste genético sem consulta prévia, ou sem um conhecimento adequado sobre as consequências para as mulheres fornecedoras do uso de seus materiais biológicos. Embora muitas mulheres possam estar inconscientes dessas práticas abusivas, elas podem resistir intuitivamente.

Em geral, ONGs feministas e movimentos sociais do Sul ligados ao gênero têm demonstrado pouco interesse em ou consciência das novas formas potenciais de exploração através das biotecnologias vermelhas, para poder ajudar mais adequadamente as mulheres, em particular, as mais pobres e vulneráveis. Mas existem algumas exceções documentadas, como, por exemplo: o papel crucial desempenhado pelo movimento de mulheres na Coréia do Sul, evidenciando as práticas fraudulentas de extração e pagamento de óvulos humanos às mulheres da equipe da sua própria pesquisa (e outras) pelo cientista e herói nacional, professor Huang; a oposição das ONGs feministas na Índia à seleção de embriões por sexo na reprodução assistida; as lutas de ONGs lideradas por mulheres e feministas pela regulamentação das novas tecnologias reprodutivas na América Latina e na pesquisa com células-tronco no Brasil. Práticas médicas eticamente duvidosas $e$ abusos dentro da reprodução assistida e dos diagnósticos genéticos, assim como as múltiplas discriminações associadas, também foram amplamente documentados e denunciados por acadêmicas e ativistas feministas do Sul (Ferreira et al., 2006; Torres; Adrião, 2014).

O movimento brasileiro de saúde afro-americana liderado por mulheres, por exemplo, solicitou, em 2012, ao Ministério da Saúde - por meio de sua participação nos conselhos locais de saúde - que inclua uma gama mais ampla e diversificada entre etnias de fontes de doação nos materiais biológicos para as pesquisas e terapias de transplantes da medula óssea.Dessa forma, se garante uma correspondência mais adequada nos registros de genes, células e tecidos com as características geneticamente diversificadas da população nacional. Diferentes tipos de pacientes na Argentina - sob a liderança da Federação Argentina de Doenças Raras, que agrupa mais de 30 associações e 15 grupos de pacientes - têm também tentado aumentar a consciência cidadã em relação às doenças e aos riscos das terapias experimentais oferecidas, além de denunciar as promessas exageradas de cura apresentadas na mídia local ${ }^{10}$.

Assim tudo, na maioria dos casos, a evidência disponível sobre genética e biotecnologia da saúde relaciona-se a mulheres de classe média, e a advocacia associada beneficia principalmente aos movimentos sociais baseados na cidade. Muito menos se sabe sobre seu uso e efeitos negativos $e$ a sua recriação criativa entre as mulheres rurais marginais dos países emergentes, as populações nativas indígenas, os diversos grupos étnicos e os grupos e movimentos civis LGBTQIA+, assim como, as populações migrantes e deslocadas. Ainda são escassos também, em nível global, os estudos empíricos sobre os resultados de ensaios clínicos em humanos para as terapias celulares em fase de desenvolvimento, bem como sobre as políticas de proteção da privacidade dos doadores de células, tecidos e óvulos, e sobre os produtos de base molecular/celular destinados a diferentes grupos de mulheres (ex. Isasi, 2012).

\section{Governança e biossocialidades globais}

Políticas de engajamento público, que procuram uma governança participativa ampla, foram elaboradas nos países avançados para conter as respostas negativas da sociedade civil a alguns dos desenvolvimentos em genética e biotecnologia. Essas estratégias políticas têm sido contraditoriamente instrumentais, contribuindo tanto para um aumento do engajamento público em direção à democratização da ciência e da medicina, quanto atuando como uma forma de legitimação adicional de interesses comerciais ou contribuindo à construção de apoio público às biotecnologias da saúde (Irwin, 2012).

\footnotetext{
${ }^{10} \mathrm{~A}$ fonte destas duas declarações é a comunicação direta com os entrevistados anônimos durante a pesquisa em andamento sob a minha coordenação.
} 
Essas políticas também têm considerado em alguns países europeus, como no Reino Unido, a promoção da ciência cidadã (Gura, 2013) - ou seja, a participação voluntária da cidadania na formulação, desenvolvimento e implementação de projetos científicos, com frequência, em nível comunitário (EGE, 2015). O impacto positivo de algumas dessas iniciativas de política pública, bem como a falta ou a incompleta resposta governamental ao sofrimento humano associado aos modelos de saúde neoliberal, levaram categorias específicas de cidadãos a se organizarem em novos tipos de associações globais (Rabeharisoa et al. 2014; Sharon, 2015).

Essas organizações reúnem-se em estruturas emergentes e alternativas de saúde e doença, muitas vezes contestadas ou em competição $\mathrm{com}$ as instituições convencionais, e são frequentemente lideradas por mulheres. Elas acostumam reforçar o caráter político e de gênero das suas atividades por meio da prática compartilhada, e se transformam em movimentos sociais sensíveis ao gênero. Brown et al. (2004) argumentam que também esses "movimentos de saúde encarnados" formam um novo subgrupo relevante - movimentos sociais limítrofes, atuando na interseção de diferentes configurações institucionais e epistêmicas ${ }^{11}$ - que tende a se tornar em uma força de mobilização social porque estabelece amplas alianças com outras redes formais e informais em saúde, por exemplo, no caso do ativismo global contra o HIV (Parker, 2011).

A crescente expansão das biotecnologias vermelhas deu origem ao "fetichismo genético", descrito por Haraway (1997:141); segundo este, o lugar de cada organismo no mundo é definido por seu banco de dados genômicos. Mas as biotecnologias vermelhas também contribuíram para novas formas de subsistência, "biossociabilidades" ou "biossocialidades" - isto é, relações sociais específicas mediadas pelas biotecnologias da saúde e que tendem a democratizar as aplicações das biociências de modo coletivo.

Indivíduos diretamente interessados na resolução de um problema de saúde tornam-se biossociais no decorrer das suas procuras; criam um enquadramento comum para a sua condição de saúde, organizam-se e envolvem-se ativamente na busca de conhecimentos e informações relevantes sobre pesquisa, ensaios clínicos e fontes de financiamento (Rabinow, 1996). As hierarquias institucionais convencionais e as relações entre pacientes, médicos e pesquisadores são recriados por esses grupos de pacientes. Eles baseiam suas práticas em suas esperanças de encontrar uma cura que, por sua vez, legitime as formas como lidam com as suas próprias doenças, assim como, com o futuro de sua categoria de doenças (Mazanderani et al., 2018; Pinto et al., 2018). No desenvolvimento de pesquisas globais com células-tronco, por exemplo, as doações de indivíduos interessados - motivados por doenças que os afetam individualmente ou a suas famílias $e$ amigos $-e$ de instituições de caridade associadas, representavam em 2008 , uma proporção maior do investimento financeiro no setor do que aquele com base em outras fontes (Franklin; Kaftantzi, 2008).

A vida se torna um recurso para a geração conjunta de saúde e riqueza compartilhada, o biovalor excede o puro lucro e utiliza-se a favor do atendimento à saúde de pacientes vulneráveis. Nas palavras de Rose (2007), a manipulação da vida gera valor na melhoria da saúde e baseada em valores éticos e morais de populações específicas. Por exemplo, Myozyme, uma terapia desenhada para a doença de Pompe através da engenharia genética celular - como estudada por Novas (2008) - foi desenvolvida em conjunto pela empresa internacional Genzyme e um grupo de pacientes do Reino Unido. Essa terapia destinava-se a satisfazer as necessidades dos pacientes não atendidos pela medicina convencional e pelo mercado, e este poderia ser considerado como um "exemplo de biossocialidade". Outras experiências de biossociabilidade, como o ativismo contra o câncer despertado em parte pelo isolamento dos vários genes BRCA de suscetibilidade a essa doença, foram documentados por Gibbons (2008) na Europa e os EUA.

Nas economias emergentes as biossocialidades são reformuladas contextualmente, segundo os seguintes estudos de caso: (a) na Índia, a reprodução assistida e a terapia celular levaram os

\footnotetext{
${ }^{11}$ Eles de- e reconstroem as demarcações entre "ciência" e "não ciência", ciência "boa" e "ruim" e estabelecem fronteiras mais porosas entre especialistas e leigos, transcendendo as atividades habitualmente executadas pelos movimentos sociais convencionais e cruzando muitos limites institucionais, pois eles se relacionam intensamente com grupos relacionados, às vezes de forma distante, a outros movimentos sociais, também aos cientistas, médicos e pesquisadores, além dos governos e algumas empresas.
} 
pobres e os doentes a se comportar como agentes de mudança através da resistência passiva, uma estratégia que eventualmente contribuiu para um câmbio substantivo na política pública (Bharadwaj, 2013); (b) na Índia, analisa-se como a violência estrutural é exercida através da biotecnologia da saúde sobre os desempregados têxteis durante um ensaio clínico de medicamentos $e$ eles recorrem simultaneamente à submissão quanto à ação coletiva rebelde (Sunder Rajan, 2008b); (c) no Equador, documentam-se as narrativas e as formas locais de biossociabilidade em relação ao intento de universalização de normas europeias para a reprodução assistida (Roberts, 2008); e (d) em 2013, a Federação Argentina de Doenças Raras junto ao Genetics Policy Institute da Califórnia estabeleceu a Rede Argentina de Pacientes para as Terapias Avançadas (APTA), um espaço de diálogo entre cientistas, reguladores e pacientes organizados que tenta fortalecer as posições dos pacientes na medicina regenerativa em nível nacional $e$ internacional (FADEPOF, 2014).

As mulheres envolvem-se também em novas formas de biossocialidade informal e baseadas na experiência, as quais muitas vezes lideram. Por exemplo, quando realizam a partilha de óvulos ou de embriões com outras mulheres e no caso das doações para a inseminação assistida e a fertilização em nível domiciliar ou em clínicas organizadas por mulheres. Os arranjos informais para a doação de gametas e embriões também costumam serem estabelecidos entre parentes, mulheres $e$ amigas das pacientes, ou entre integrantes de uma determinada orientação sexual. Muitas vezes, nessas práticas os direitos de propriedade e exclusividade são reformulados como direitos cooperativos ou comunais dentro da "recriação criativa", quando as mulheres exercem seus direitos à cidadania biopolítica nas novas formas de biossocialidade.

\section{Considerações finais}

Ao longo deste artigo se colocaram conceitos teóricos e exemplos em relação às maneiras pelas quais acadêmicos, ativistas feministas e mulheres leigas recriam os efeitos negativos das tecnologias em análise, definem seus limites e os utilizam em seu benefício. O reagrupamento de pacientes para encontrar soluções criativas para o seu sofrimento e desenvolver ativamente novos conhecimentos; as iniciativas informais lideradas por mulheres para a inseminação artificial; o controle do tráfico de materiais biológicos e do turismo médico para a experimentação com terapias celulares não comprovadas são alguns dos esforços que moldam novas formas de convívio por meio da biopolítica e da biossocialidade.

Os processos históricos têm um modo de se desdobrar dialeticamente. Enquanto se expande a acumulação do biocapital $e$ a disciplina do biopoder é exercida através do corpo, e em alguns casos se intenta exercer a necrobiopolítica, os cidadãos biopolíticos em geral, $e$ as mulheres em especial, aumentam sua proatividade em responsabilidade genética, desenvolvem uma nova ética corporal e criam formas inovadoras de biossociabilidade. Luta-se por novos direitos genéticos e biotecnológicos que se conquistam, individual e coletivamente, em nível local e global.

A compreensão feminina dessas questões com base na experiência é particularmente relevante, uma vez que muitas das aplicações das tecnologias analisadas visam diretamente à sua saúde e seus corpos, por exemplo, os diagnósticos genéticos, as vacinas moleculares, a contracepção de base biológica, os processos reprodutivos assistidos e as intervenções genéticas com transmissão eventual das modificações genéticas de forma intergeracional. Em essas experiências "localizadas", as mulheres participam da recriação da própria vida, e as biotecnologias da saúde e a genética podem-se recuperar para o bem comum (Dickenson, 2016).

Mas os conhecimentos específicos das mulheres podem ser mais sistematicamente incluídos nos processos democráticos de participação social, econômica e política e adquirir uma maior visibilidade, através de seu autorreconhecimento como cidadãs com novos direitos, e através de seu engajamento coletivo nos novos processos e espaços abertos para a cidadania biopolítica. Movimentos sociais de saúde "encarnados", como os já descritos, podem catalisar mudanças, influenciar a formulação de políticas e contribuir ativamente para transformar as regras do jogo; colocando as pessoas em primeiro lugar - antes dos biomercados, do biovalor e da necropolítica. As mulheres dos países emergentes podem encontrar novas oportunidades dentro do novo cenário 
geral, que incluam o reconhecimento equilibrado $e$ informado do novo paradigma em questão $e$ sirvam de suporte de um novo tipo de empoderamento em nível individual e coletivo.

\section{Referências bibliográficas}

AGAMBEN, Giorgio. Homo sacer: o poder soberano e a vida nua. Belo Horizonte, Editora UFMG, 2010.

BEESON, Diane; LIPPMAN, Abby. Egg-harvesting for Stem-Cell Research -- Medical Risks and Ethical Problems. Alliance for Humane $\quad$ Biotechnology, 2007 [http://www.rbmonline.com/4DCGI/Article/Article?38\%091\%09=\%202503\%09 - acesso em: 15 jun 2019].

BHARADWAJ, Aditya. Ethic of consensibility, subalternethicality: the clinical application of embryonicstem cells in India. BioSocieties (8), 2013, pp.25-40.

BIRCH, Kean; TYFIELD, David. Theorizing the Bioeconomy: Biovalue, Biocapital, Bioeconomics or...What? $\begin{array}{lllll}\text { Science, } & \text { Technology } \& \quad H u m a n & \text { Values, } & 012\end{array}$ [http://citeseerx.ist.psu.edu/viewdoc/download?doi=10.1.1.969.8878\&rep=rep1\&type $=$ pdf - acesso em: 11 jul 2019].

BORTZ, Gabriela; VASEN, Federico; ROSEMANN, Achim. Construção das terapias com células-tronco na Argentina: regulação, gestão de riscos e políticas de inovação. Sociologias [online], (2), n. 50, 2019, pp.116-155.

BRAIDOTTI, Rossy. Posthuman Affirmative Politics In: S.E. WILMER, Sam; ZUKAUSKAITE, Audronè (ed.). Resisting Biopolitics: Philosophical, Political, and Performative Strategies. New York, Routledge, 2015, pp.30-57.

BRAIDOTTI, Rossy. Posthuman Humanities. European Educational Research Journal (12),n. 1, 2013, pp.119.

BROWN, Phil et alii. Embodied health movements: new approaches to social movements in health. Sociology of Health \&Illness, (26), n. 1, 2004, pp.50-80.

DARLING, Marcia. Gender, New Technologies and Development. In: HARCOURT, Wendy; DARLING, Marcia; WOLBRING, Catherine (ed.). New Technologies and Development. Development, Journal of the Society for International Development, (49), n. 4, 2006, pp.23-27.

DARNOVSKY, Marcy. FDA halts 23 and Me personal genetic tests. Medical Laboratory Observer. Março 19, 2014 [https://www.mlo-online.com/home/article/13006245/fda-halts-23andme-personal-genetic-tests acesso em: 17 Mai 2019].

DICKENSON, Donna. Me Medicine vs. We Medicine: Reclaiming Biotechnology for the Common Good. New York, Columbia University Press, 2016.

DICKENSON, Donna. Body Shopping: Converting Body Parts to Profit. Oxford, One World Publications, 2008.

DICKENSON, Donna; DARNOVSKY, Marcy. Did a permissive scientific culture encourage the "CRISPR babies" experiment? Nature Biotechnology (37), 2019, pp.355-357.

EINSIEDEL, E.; ADAMSON, H. Stem cell tourism and future stem cellt ourists: policy and ethical implications. Developing World Bioethics, v. 12, n. 1, 2012, pp.35-44.

EUROPEAN Group on Ethics in Science and New Technologies (EGE). Opinion n. 29. The ethical implications of new health technologies and citizen participation. Brussels, European Commission, 2015 [https://publications.europa.eu/en/publication-detail/-/publication/e86c21fa-ef2f-11e5-8529-

01aa75ed71a1/language-en/format-PDF/source-77404221- acesso em: 12 jan. 2019].

FEDERACIÓN Argentina de Enfermedades Poco Frecuentes (FADEPOF). Informe sobre ensayo clínico con células madres en pacientes con lesiones oculares, Nov. 2, 2014 [http://fadepof.org.ar/noticias/53 - acesso em: 7 ago 2019].

FERREIRA, Verônica; ÁVILA, Maria Betania; PORTELLA, Ana Paula (org.). Feminismo e novas tecnologias reprodutivas. Recife, SOS Corpo, 2006. 
FRANKLIN, Sarah; KAFTANTZI, Louise. Industry in the Middle: Interview with Intercytex Founder and CSO, Dr Paul Kemp. Science as Culture, Special Issue on Stem Cells, Part II (17), n. 4, 2008, pp.449-462.

FRANKLIN, Sarah; LOCK, Margaret. Remaking Life and Death: Toward an Anthropology of the Biosciences. London, Palgrave, 2003.

GIBBON, Sarah. Charity, breast cancer activism and the iconic figure of the BRCA Carrier. In: GIBBON, Sarah; NOVAS, Carlos (ed.). Genetics, Biossocialities and the Social Sciences: Making Biologies and Identities. Oxon, Routledge, 2008, pp.19-37.

GURA, Theodore. Citizen Science: Amateur experts. Nature (496), 2013, pp.259- 262.

HARAWAY, Donna. Modest_Witness@Second_Millenium. FemaleMan@_Meets_Oncomouse ${ }^{T M}$. London, Routledge, 1997.

HARAWAY, Donna. A Cyborg Manifesto: Science, Technology and Socialist-Feminism in the Late Twentieth Century. In: HARAWAY, Donna (ed.). Simians, Cyborgs, and Women: The Reinvention of Nature. New York, Routledge, 1991a, pp.149-183.

HARAWAY, Donna. Situated Knowledges: The Science Question in Feminism and the Privilege of Partial Perspective. In: HARAWAY, Donna, Simians, Cyborgs, and Women: The Reinvention of Nature, New York, Routledge, 1991b, pp.183-203.

HARCOURT, Wendy. Editorial: Where Did All the Flowers Go?: Contradictions in world economies. In: HARCOURT, Wendy (ed.). Sustaining local economies. Development. (53), n. 3, 2010, pp.301-304.

HARVEY, Michael; MC MEEKIN, Andy. Publicor Private Economies of Knowledge? Turbulence in the Biological Sciences. London, Edward Elgar, 2007.

HWANG, Seyoung; SLEEBOOM-FAULKNER, Margaret. Bioethical governance in South Korea: tensions between bottom-up movements and professionalization, and scientific citizenship. East Asian Science, Technology and Society: An International Journal (8), n 2, 2014, pp.209-228.

INTERNATIONAL Cellular Medicine Society (ICMS). Presidential Task Force on the Use of Unproven Cellular Therapies. Reference Guide, 2015 [http://www.celltherapysociety.org/?page=PTF2015 - acesso em: 22 jan. 2019].

INTERNATIONAL Society For Stem Cell Research (ISSRC). Patient Handbook on Stem Cell Therapies. A Report from the International Society for Stem Cell Research. London, ISSRC, 2008 [https://www.closerlookatstemcells.org/patient-resources/ - acesso em: 22 dez. 2018].

IRWIN, Alan; ELGAARD, Torben; JONES, Kevin. The good, the bad and the perfect: Criticizing engagement practice. Social Studies of Science (43), n. 1, 2012, pp.118-135.

ISASI, Rosario et.al. Disclosure and management of research findings in stem cell research and banking: policy statement. Regenerative Medicine (7),n.3, 2012, pp.439-448.

KASS, Leon. Science, Religion, and the Human Future. Commentary, 2007, pp.36-48.

KURIYAN, Ajay et al. Vision loss after intravitreal injection of autologous "stem cells" for AMD. New England Journal of Medicine (376), 2017, pp.1047-1053.

LOCK, Margaret. Comprehending the body in the era of the epigenome. Current Anthropology (56), 2015, pp.151-177.

LUCIANO, Dana; CHEN, Mel. Has the Queer Ever Been Human? GLQ: A Journal of Lesbian and Gay Studies (21), n. 2-3, 2015, pp.182-195.

MAC DOWELL DOS SANTOS, Maria Cecilia. Quem pode falar, onde e como: uma conversa "não o inocente" com Donna Haraway. cadernos pagu (5), Campinas, Núcleo de Estudos de GêneroPagu/Unicamp, 1995, pp.43-72.

MAC MAHON, Dominique. The global industry for unproven stem cell interventions and stem cell tourism. Tissue Engineering and Regenerative Medicine, (11), n. 1, 2014, pp.1-9.

MARGOTTINI, Laura. Italian Parliament Orders€3 Million Trial of Disputed Therapy. Science (340), 31 May 2013,pp.6136 [https://science.sciencemag.org/content/340/6136/1028 - acesso em: 15 jun. 2019]. 
MAZANDERANI, Fadhila; KELLY, Jenny; DUCEY, Ariel. From embodied risk to embodying hope: Therapeutic experimentation and experiential information sharing in a contested intervention for Multiple Sclerosis. Biosocieties (13), n. 1, 2018, pp.232-254.

MBEMBE, Achille. Necropolitics. Public Culture, 15, 2003, pp.11-40.

MONSORES, Natan; LOPES, Cecilia; BESSA BEZERRA, Edilnete; LUNARA SILVA, Natasha. Netnografia e análise bioética de blogs de turismo terapêutico com células-tronco. Ciência e saúde coletiva 21 (10), 2016 [https://www.scielosp.org/article/csc/2016.v21n10/3049-3059/ - acesso em: 24 mai 2019].

MORE, Max. The Extropian Principles: A Transhumanist Declaration, 1999 [http://www.extropy.org/extprn3.htm. - acesso em: 11maio 2019].

NIOSI, Jorge; HANEL, Ptr; REID, Susan. The international diffusion of biotechnology: the arrival of developing countries. Journal of Evolutionary Economics, online, 2012 [https://www.researchgate.net/profile/Jorge_Niosi2/publication/234074296_The_International_Diffusion_of _Biotechnologies/links/57a3c06e08ae3f4529250812.pdf - acesso em: 14 mai 2019].

PARKER, Richard. Grassroots Activism, Civil Society Mobilization, and the Politics of the Global HIV/AIDS Epidemic. The Brown Journal of World Affairs (17), n. 2, 2011, pp.21-37.

PETROPANAGOS, Angel; CATTAPAN, Alana; BAYLIS, Francoise; LEADER, Arthur. Social eggfreezing: risk, benefits and other considerations. Canadian Medical Association Journal (16), v.187, n. 9, 2015, pp.666669.

PINTO, Deirdre; MARTIN, Dominique; CHENHALL, Richard. Chasing cures: Rewards and risks for rare disease patient organizations involved in research. Biosocieties (13), n. 1, 2018, pp.123-147.

PEREZ REQUEJO, José Luis; AZNAR LUCEA, Jorge. Turismo de células madre. Medicina e Morale (1), 2012, pp.32-56.

PRECIADO, Beatriz. The Pharmaco-pornographic Regime: Sex, Gender, and Subjectivity in the Age of Punk Capitalism. In: STRYKER, Susan; AIZURA, Aren (ed.). Transgender Studies Reader (2), 2006, pp.271-284.

RABERHARISOA, Vololona et alii. From "politics of numbers" to "politics of singularisation": Patients' activism and engagement in research on rare diseases in France and Portugal. Biosocieties (9), n. 2, 2014, pp.194-217.

RABINOW, Paul. Artificiality and enlightenment: From sociobiology to biossociality. In: RABINOW, Paul. Essays on the anthropology of reason. Princeton, NJ, Princeton University Press, 1996, pp.91-107.

RABINOW, Paul; ROSE, Nikolas. Biopower today. Biosocieties (1), 2006, pp.195-217.

RABINOW, Paul; ROSE, Nikolas (ed.). The essential Foucault: Selections from essential works of Foucault, 1954-1984. New York and London, New Press, 2003.

RAPP, Rayna. Testing Women, Testing the Fetus: The Social Impact of Amniocentesis in America. New York, Routledge, 2000.

RISOY, S.; SIRNES, T. The decision: Relations to oneself, authority and vulnerability in the field of selective abortion. Biosocieties (10), n. 3, 2015, pp.317-340.

ROSE, Nikolas. The human sciences in a biological age. Theory Culture \& Society (30), 2013, pp.3-34.

ROSE, Nikolas. The Politics of Life Itself: Biomedicine, Power, and Subjectivity in the Twenty-First Century. Oxford, Princeton University Press, 2007.

ROSE, Nikolas; NOVAS, Carlos. Biological citizenship. In: ONG, Andrew; COLLIER, Susan (ed.). Global assemblages: Technology, politics and ethics as anthropological problems. Malden, MA, Blackwell Publishing, 2005, pp.439-63.

ROSEMANN, Achim; BORTZ, Gabriela; VASEN, Federico. Regulatory developments for non hematopoietic stem cell therapeutics: perspectives from the EU, the USA, Japan, China, India, Argentina, and Brazil. In: CHEN, Xiao-Dong (org.). A road map to non-hematopoietic stem cell-based therapeutics. From the bench to the clinic. Londres, Elsevier, 2018, pp.463-92.

SHARON, T Healthy citizenship beyond autonomy and discipline: Tactical engagements with genetic testing. Biosocieties (10), n. 3, 2015, pp.295-316. 
SLEEBOOM-FAULKNER, Margaret. The large grey are a between "bonafide" and "rogue" stem cell interventions ethical acceptability and the need to include local variability. Technological Forecasting and Social Change, (109), 2016, pp.76-86.

SUNDER RAJAN, Kaushik. Genomic Capital: Public Cultures and market Logics of Corporate Biotechnology. Science as Culture, Online, (9), 2008a, pp.87-121.

SUNDER RAJAN, Kaushik. Biocapital as an emergent form of life: speculations on the figure of the experimental subject. In: GIBBON, Sarah; NOVAS, Carlos (ed.) Genetics, Biossocialities and the Social Sciences: Making Biologies and Identities. Oxon, Routledge, 2008b, pp.157-188.

THACKER, Eugene. Data MadeFlesh: BiotechnologyandthediscourseofthePosthuman. Cultural Critique (53), 2003, pp.72-97.

THORSTEINSDÓTTIR, Halla et alii. Introduction: promoting global health through biotechnology. Nature Biotechnology (22), Supplement, 2004, pp.DC3-DC7.

WALDBY, Catherine. Oocyte markets: women's reproductive work in ESCR. New Genetics and Society (27), n. 1, 2008, pp.19-31.

WALDBY, Catherine. Tissue cultures and the production of biovalue. Health (6), 2002, pp.305-323.

WORLD Health Organization (WHO). Genomics and World Health. Geneva, WHO, The Advisory Committee on Health Research, 2002.

YOXEN, E. Life as a productive force: capitalizing upon research in molecular biology. In: LEVIDOW, Lynn; YOUNG, Robert (ed.). Science, Technology, and the Labour Process. London, Blackrose Press, 1981, pp.66-122. 